\title{
Winogradskyella echinorum sp. nov., a marine bacterium of the family Flavobacteriaceae isolated from the sea urchin Strongylocentrotus intermedius
}

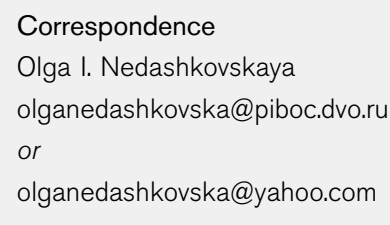

The genus Winogradskyella was created to accommodate heterotrophic, aerobic, yellow-pigmented, Gram-negative and motile (gliding) bacteria (Nedashkovskaya et al., 2005). At the time of writing, the genus comprises four recognized species: Winogradskyella epiphytica, Winogradskyella eximia, Winogradskyella poriferorum and Winogradskyella thalassocola (Lau et al., 2005; Nedashkovskaya et al., 2005). The type strains of the species in the genus Winogradskyella were isolated from the green alga Acrosiphonia sonderi, from the brown algae Chorda filum and Laminaria japonica (collected in the East Sea, also known as the Sea of Japan) and from the sponge Lissodendoryx isodictyalis (collected in the Bahamas). Representatives of the genus Winogradskyella were also found during a study of bacterial communities of Arctic pack ice, from North Sea green alga (Enteromorpha) and from coastal surface water (Alonso et al., 2007; Brinkmeyer et al., 2003; Patel et al., 2003).

The aim of this study was to determine the precise taxonomic position of a sea urchin-associated micro-

The GenBank/EMBL/DDBJ accession number for the 16S rRNA gene sequence of strain $\mathrm{KMM} 6211^{\top}$ is EU727254. organism, designated strain $\mathrm{KMM} 6211^{\mathrm{T}}$, by using a polyphasic approach. The results of a phylogenetic analysis based on $16 \mathrm{~S}$ rRNA gene sequences revealed that the novel isolate belonged to the family Flavobacteriaceae and occupied a distinct lineage within the genus Winogradskyella.

Strain $\mathrm{KMM} 6211^{\mathrm{T}}$ was isolated from a sea urchin (Strongylocentrotus intermedius) collected in Troitsa Bay in the Gulf of Peter the Great of the East Sea (also known as the Sea of Japan). For strain isolation, $0.1 \mathrm{ml}$ homogenates of sea-urchin tissues were transferred onto plates of marine agar 2216 (Difco). After primary isolation and purification, the strain was cultivated at $28{ }^{\circ} \mathrm{C}$ on the same medium and stored at $-80{ }^{\circ} \mathrm{C}$ in marine broth 2216 (Difco) supplemented with $20 \%$ (v/v) glycerol.

Genomic DNA extraction, PCR and sequencing of the 16S rRNA gene were performed according to procedures described previously (Vancanneyt et al., 2004). The sequence data obtained were aligned with those of representative members of selected genera belonging to the family Flavobacteriaceae by using PHYDIT, version 3.2 
(http://plaza.snu.ac.kr/ jchun/phydit/). Phylogenetic trees were inferred by using suitable programs in the PHYLIP package (Felsenstein, 1993). Phylogenetic distances were calculated by using the model of Jukes \& Cantor (1969) and the tree was constructed with the neighbour-joining (Saitou \& Nei, 1987) method. Phylogenetic trees were also constructed by using the maximum-likelihood and maximum-parsimony methods (Felsenstein, 1993). Bootstrap analysis was performed with 100 resampled datasets, using the SEQBOOT and CONSENSE programs of the PHYLIP package.

A phylogenetic analysis of almost-complete 16S rRNA gene sequences indicated that strain $\mathrm{KMM} 6211^{\mathrm{T}}$ was a member of the family Flavobacteriaceae and formed a distinct branch within the genus Winogradskyella (Fig. 1). The levels of $16 \mathrm{~S}$ rRNA gene sequence similarity between strain KMM $6211^{\mathrm{T}}$ and the type strains of species in the genus Winogradskyella ranged from 95.2 to $97.1 \%$. Although $W$. eximia KMM $3944^{\mathrm{T}}$ was the closest relative of the novel isolate $(97.1 \%$ sequence similarity), the tree topology showed that strain KMM $6211^{\mathrm{T}}$ clustered with $W$. poriferorum UST030701-295 ${ }^{\mathrm{T}}$ (Fig. 1).

DNA was isolated by following the method of Marmur (1961) and the DNA G + C content was determined by using the thermal denaturation method (Marmur \& Doty, 1962). The DNA G+C content of $\mathrm{KMM} 6211^{\mathrm{T}}$ was $33.6 \mathrm{~mol} \%$.

To determine whole-cell fatty acid and polar lipid profiles, strain $\mathrm{KMM} 6211^{\mathrm{T}}$ was grown at $28{ }^{\circ} \mathrm{C}$ for $48 \mathrm{~h}$ on marine agar 2216. The polar lipids and fatty acid methyl esters were extracted and analysed as described previously (Nedashkovskaya et al., 2006).

Phosphatidylethanolamine was the only phospholipid identified. The predominant cellular fatty acids of strain KMM $6211^{\mathrm{T}}$ were straight-chain unsaturated, branchedchain unsaturated and saturated, namely iso- $\mathrm{C}_{15: 1}$, iso$\mathrm{C}_{15: 0}$, summed feature 3 (consisting of iso- $\mathrm{C}_{15: 0} 2-\mathrm{OH}$ and/or $\left.\mathrm{C}_{16: 1} \omega 7 c\right), \mathrm{C}_{15: 0}$, iso- $\mathrm{C}_{15: 0} 3-\mathrm{OH}$ and iso- $\mathrm{C}_{17: 0} 3-$ $\mathrm{OH}$. These values are consistent with those reported for recognized members of the genus Winogradskyella (Lau et al., 2005; Nedashkovskaya et al., 2005).
The physiological, morphological and biochemical characteristics of strain KMM $6211^{\mathrm{T}}$ were tested as described previously (Nedashkovskaya et al., 2003, 2004). API 20NE and API ZYM galleries (bioMérieux) were also used for studying the phenotypic features of the strain; they were performed according to the manufacturer's instructions, except that the galleries were incubated at $28{ }^{\circ} \mathrm{C}$.

The main physiological and biochemical characteristics are given in the species description and in Table 1. Phenotypic similarities between KMM $6211^{\mathrm{T}}$ and Winogradskyella species support the classification of the strain within the genus Winogradskyella. Like other Winogradskyella species, the novel isolate demonstrates oxidase, catalase, alkaline phosphatase and gelatinase activities, requires $\mathrm{Na}^{+}$ions for growth and moves by gliding (Table 1). However, in contrast with the recognized Winogradskyella species, strain KMM $6211^{\mathrm{T}}$ shows $\beta$-galactosidase activity and lacks esterase (Tween 40) activity. Strain KMM 6211 ${ }^{\mathrm{T}}$ clearly differs from its closest phylogenetic relative, $W$. eximia KMM $3944^{\mathrm{T}}$, in terms of hydrolysis of agar and starch, growth at $37{ }^{\circ} \mathrm{C}$, acid production from D-glucose, maltose, sucrose and mannitol and utilization of sucrose and mannitol (Table 1). The traits that serve to distinguish strain $\mathrm{KMM} 6211^{\mathrm{T}}$ from the recognized Winogradskyella species are shown in Table 1.

Therefore, the data obtained in this polyphasic analysis confirm that strain KMM $6211^{\mathrm{T}}$ represents a novel species of the genus Winogradskyella, for which the name Winogradskyella echinorum sp. nov. is proposed.

\section{Description of Winogradskyella echinorum sp. nov.}

Winogradskyella echinorum (e.chi.no'rum. L. masc. n. echinus sea urchin; N.L. gen. pl. n. echinorum of echini, sea urchins, referring to the isolation of the type strain from a sea urchin).

Cells are Gram-negative rods that are motile by gliding, $0.4-0.5 \mu \mathrm{m}$ wide and $1.2-2.7 \mu \mathrm{m}$ long. On marine agar 2216 , colonies are $1-2 \mathrm{~mm}$ in diameter, circular, shiny with entire edges and are pigmented bright yellow. Growth occurs at $4-37{ }^{\circ} \mathrm{C}$ and with $1-6 \% \mathrm{NaCl}$. Produces oxidase,

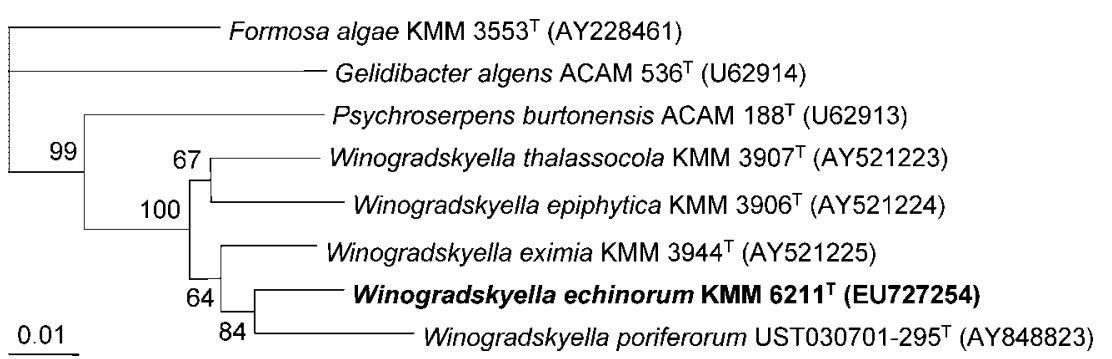

Fig. 1. Neighbour-joining phylogenetic tree, based on 16S rRNA gene sequences, showing the relationship between strain $\mathrm{KMM}$ $6211^{\top}$ and type strains of species of the genus Winogradskyella. The tree was constructed by using Jukes-Cantor evolutionary distances. Numbers at nodes indicate bootstrap percentages (based on 100 resampled datasets). Exactly the same topology was recovered in the maximum-likelihood and maximum-parsimony trees (data not shown). Bar, 0.01 substitutions per nucleotide position. 
Table 1. Phenotypic features of $\mathrm{KMM} 6211^{\top}$ and strains of the recognized Winogradskyella species

Taxa: 1, KMM $6211^{\mathrm{T}}$; 2, W. thalassocola KMM $3907^{\mathrm{T}}$; 3, W. epiphytica KMM $3906^{\mathrm{T}}$; 4, W. eximia $\mathrm{KMM} 3944^{\mathrm{T}} ; 5$, W. poriferorum UST030701-295 ${ }^{\mathrm{T}}$. Data are from Lau et al. (2005), Nedashkovskaya et al. (2005) and this study. All strains were positive for the following: respiratory metabolism; gliding motility; oxidase, catalase and alkaline phosphatase activities; a requirement for $\mathrm{Na}^{+}$ions for growth; gelatin hydrolysis; susceptibility to carbenicillin and lincomycin; and resistance to benzyl penicillin, gentamicin, kanamycin, neomycin, polymyxin B and streptomycin. All strains were negative for the following: nitrate reductase activity; flexirubin-type pigments; indole and acetoin production; hydrolysis of urea and chitin; acid production from L-arabinose, D-galactose, D-lactose, melibiose, Lrhamnose, D-xylose, adonitol, dulcitol, inositol, sorbitol and citrate; and utilization of L-arabinose, D-lactose, inositol, sorbitol, malonate and citrate. ND, Data not available.

\begin{tabular}{|c|c|c|c|c|c|}
\hline Characteristic & 1 & 2 & 3 & 4 & 5 \\
\hline$\beta$-Galactosidase activity & + & - & - & - & - \\
\hline \multicolumn{6}{|l|}{ Degradation of: } \\
\hline Agar & - & + & + & + & - \\
\hline Casein & + & - & - & + & - \\
\hline Starch & - & - & - & + & - \\
\hline Tween 20 & - & - & + & + & + \\
\hline Tween 40 & - & + & + & + & + \\
\hline Tween 80 & - & - & + & - & + \\
\hline DNA & + & - & + & - & + \\
\hline \multicolumn{6}{|l|}{ Growth at/with: } \\
\hline $37{ }^{\circ} \mathrm{C}$ & + & - & + & - & + \\
\hline $44{ }^{\circ} \mathrm{C}$ & - & - & - & - & + \\
\hline $8 \% \mathrm{NaCl}$ & - & + & + & - & - \\
\hline \multicolumn{6}{|l|}{ Acid formation from: } \\
\hline D-Glucose & - & + & - & + & - \\
\hline Maltose & - & + & - & + & - \\
\hline Cellobiose & - & + & - & - & - \\
\hline Sucrose & - & - & - & + & - \\
\hline Mannitol & - & - & - & + & - \\
\hline \multicolumn{6}{|l|}{ Utilization of: } \\
\hline D-Glucose & + & + & - & + & - \\
\hline D-Mannose & + & + & - & + & - \\
\hline Sucrose & - & - & - & + & - \\
\hline Mannitol & - & - & - & + & - \\
\hline \multicolumn{6}{|l|}{ Susceptibility to: } \\
\hline Ampicillin & - & - & + & - & + \\
\hline Oleandomycin & + & + & + & - & $\mathrm{ND}$ \\
\hline Tetracycline & - & - & + & + & + \\
\hline DNA G $+C$ content $(\mathrm{mol} \%)$ & 33.6 & 34.6 & 35.2 & 36.1 & 32.8 \\
\hline
\end{tabular}

catalase, $\beta$-galactosidase and alkaline phosphatase. Degrades aesculin (weakly), gelatin, casein and DNA. Does not hydrolyse agar, starch, Tweens 20,40 or 80 , cellulose (CM-cellulose or filter paper) or chitin. Does not produce acid from L-arabinose, cellobiose, D-galactose, Dglucose, D-fructose, D-lactose, maltose, melibiose, raffinose, L-rhamnose, sucrose, D-xylose, $N$-acetylglucosamine, glycerol, inositol, sorbitol or mannitol. Utilizes D-glucose and
D-mannose, but not L-arabinose, D-lactose, maltose, sucrose, $\mathrm{N}$-acetylglucosamine, adipate, caprate, citrate, gluconate, malate, phenyl acetate, inositol, mannitol or sorbitol. In the API ZYM gallery, esterase C4, esterase lipase C8, leucine, cystine and valine arylamidases, $\alpha$ chymotrypsin, acid phosphatase and naphthol-AS-BIphosphohydrolase activities are present, but lipase C14, trypsin, $\alpha$-galactosidase, $\beta$-glucuronidase, $\alpha$ - and $\beta$-glucosidases, $N$-acetyl- $\beta$-glucosaminidase, $\alpha$-mannosidase and $\alpha$ fucosidase activities are absent. Nitrate is not reduced. $\mathrm{H}_{2} \mathrm{~S}$, indole and acetoin (Voges-Proskauer reaction) are not produced. Susceptible to carbenicillin, chloramphenicol, erythromycin, lincomycin and oleandomycin, but resistant to ampicillin, benzyl penicillin, doxycycline, gentamicin, kanamycin, neomycin, polymyxin B, streptomycin and tetracycline. Phosphatidylethanolamine is the only phospholipid detected. The predominant fatty acids are iso$\mathrm{C}_{15: 1}$, iso- $\mathrm{C}_{15: 0}$, summed feature 3 (consisting of iso- $\mathrm{C}_{15: 0}$ $2-\mathrm{OH}$ and/or $\left.\mathrm{C}_{16: 1} \omega 7 c\right), \mathrm{C}_{15: 0}$, iso- $\mathrm{C}_{15: 0} 3-\mathrm{OH}$ and iso$\mathrm{C}_{17: 0} 3-\mathrm{OH}$. The DNA G $+\mathrm{C}$ content of the type strain is $33.6 \mathrm{~mol} \%$.

The type strain, KMM $6211^{\mathrm{T}}\left(=\mathrm{KCTC} 22026^{\mathrm{T}}=\mathrm{LMG}\right.$ $24757^{\mathrm{T}}$ ), was isolated at Troitsa Bay in the East Sea (also known as the Sea of Japan) from the sea urchin Strongylocentrotus intermedius.

\section{Acknowledgements}

This research was supported by grants from the Russian Foundation for Basic Research (no. 08-04-00099), the Presidium of the FarEastern Branch of the Russian Academy of Sciences (no. 06-III-A-06183) and the Presidium of the Russian Academy of Sciences 'Molecular and Cell Biology'.

\section{References}

Alonso, C., Warnecke, F., Amann, R. \& Pernthaler, J. (2007). High local and global diversity of Flavobacteria in marine plankton. Environ Microbiol 9, 1253-1266.

Brinkmeyer, R., Knittel, K., Jürgens, J., Weyland, H., Amann, R. \& Helmke, E. (2003). Diversity and structure of bacterial communities in Arctic versus Antarctic pack ice. Appl Environ Microbiol 69, 66106619.

Felsenstein, J. (1993). PHYLIP (phylogeny inference package), version 3.5c. Distributed by the author. Department of Genome Sciences, University of Washington, Seattle, USA.

Jukes, T. H. \& Cantor, C. R. (1969). Evolution of protein molecules. In Mammalian Protein Metabolism, vol. 3, pp. 21-213. Edited by H. N. Munro. New York: Academic Press.

Lau, S. C. K., Tsoi, M. M. Y., Li, X., Plakhotnikova, I., Dobretsov, S., Lau, K. W. K., Wu, M., Wong, P. K., Pawlik, J. R. \& Qian, P. Y. (2005). Winogradskyella poriferorum sp. nov., a novel member of the family Flavobacteriaceae isolated from a sponge in the Bahamas. Int J Syst Evol Microbiol 55, 1589-1592.

Marmur, J. (1961). A procedure for the isolation of deoxyribonucleic acid from microorganisms. J Mol Biol 3, 208-218.

Marmur, J. \& Doty, P. (1962). Determination of the base composition of deoxyribonucleic acid from its thermal denaturation temperature. J Mol Biol 5, 109-118. 
Nedashkovskaya, O. I., Kim, S. B., Han, S. K., Lysenko, A. M., Rohde, M., Zhukova, N. V., Falsen, E., Frolova, G. M., Mikhailov, V. V. \& Bae, K. S. (2003). Mesonia algae gen. nov., sp. nov., a novel marine bacterium of the family Flavobacteriaceae isolated from the green alga Acrosiphonia sonderi (Kütz) Kornm. Int J Syst Evol Microbiol 53, 1967-1971.

Nedashkovskaya, O. I., Kim, S. B., Han, S. K., Rhee, M. S., Lysenko, A. M., Falsen, E., Frolova, G. M., Mikhailov, V. V. \& Bae, K. S. (2004). Ulvibacter litoralis gen. nov., sp. nov., a novel member of the family Flavobacteriaceae isolated from the green alga Ulva fenestrata. Int $J$ Syst Evol Microbiol 54, 119-123.

Nedashkovskaya, O. I., Kim, S. B., Han, S. K., Snauwaert, C., Vancanneyt, M., Swings, J., Kim, K. O., Lysenko, A. M., Rohde, M. \& other authors (2005). Winogradskyella thalassocola gen. nov., sp. nov., Winogradskyella epiphytica sp. nov. and Winogradskyella eximia sp. nov., marine bacteria of the family Flavobacteriaceae. Int J Syst Evol Microbiol 55, 49-55.
Nedashkovskaya, O. I., Kim, S. B., Zhukova, N. V., Kwak, J., Mikhailov, V. V. \& Bae, K. S. (2006). Mesonia mobilis sp. nov., isolated from seawater, and emended description of the genus Mesonia. Int J Syst Evol Microbiol 56, 2433-2436.

Patel, P., Callow, M., Joint, I. \& Callow, J. (2003). Specificity in the settlement - modifying response of bacterial biofilms towards zoospores of the marine alga Enteromorpha. Environ Microbiol 5, 338-349.

Saitou, N. \& Nei, M. (1987). The neighbor-joining method: a new method for reconstructing phylogenetic trees. Mol Biol Evol 4, 406425.

Vancanneyt, M., Mengaud, J., Cleenwerck, I., Vanhonacker, K., Hoste, B., Dawyndt, P., Degivry, M. C., Ringuet, D., Janssens, D. \& Swings, J. (2004). Reclassification of Lactobacillus kefirgranum Takizawa et al. 1994 as Lactobacillus kefiranofaciens subsp. kefirgranum subsp. nov. and emended description of L. kefiranofaciens Fujisawa et al. 1988. Int J Syst Evol Microbiol 54, 551-556. 